\title{
Investigation of Correct Application of Ventilators' Humidifier Systems Before and After Nursing Education in Intensive Care Units
}

\author{
Seyyed Mohsen Pouryaghobi ${ }^{1}$, Mojtaba Ahmadinejad ${ }^{2}$, Leila Hajimaghsoudi ${ }^{2}$, \\ Mohsen Ebrahimi ${ }^{3}$, Ehsan Bolvardi ${ }^{3}$, Amir Masoud Hashemian ${ }^{3}$ and \\ Koorosh Ahmadi ${ }^{4 *}$ \\ ${ }^{1}$ Department of Anesthesiology,Alborz University of Medical Sciences,Karaj,Iran. \\ ${ }^{2}$ Department of Surgery, Alborz University of Medical Sciences,Karaj,Iran. \\ ${ }^{3}$ Assistant Professor of Emergency Medicine, Mashhad University of Medical Sciences, Mashhad, Iran. \\ ${ }^{4}$ Associate Professor of Emergency Medicine, Alborz University of Medical Sciences,Karaj,Iran.
}

DOI: http://dx.doi.org/10.13005/bbra/1962

(Received: 18 September 2015; accepted: 29 November 2015)

\begin{abstract}
Provision of inspiratory humidity in patients connected to ventilator prevents drying and increasing the density of airway secretions, airway obstruction and following complications. Nursing stuff plays an important role at the correct application of ventilator's humidifiers. In this study we evaluate the effect of nursing education on the correct application of ventilator's humidifiers in intensive care units. This research was done as a randomized double blind study at two stages: At first step, 327 connected ventilators to patient were investigated according to the presence of humidifier, distilled water in the humidifier's container, connection tubes, connectors and connection of humidifier system to inspiratory arm. Then nursing education was done for correct application of ventilator's humidifiers in intensive care units, without previous information about research proposal. At second step, after the nursing education, all stages similar to first step were repeated and the data were recorded in questionnaire. Data were analyzed by SPSS software, Chi- square and fisher tests. According to analysis of data statically, before and after nursing education: The \%91.40 and \%82.60 of ventilators had humidifier system, respectively, which the reduction was statically significant $(P=$ $0.001)$. The $\% 49.80$ and $\% 65.20$ of humidifier systems had connectors and connective tubes, which the increase was statically significant $(P=0.00)$. The \%39.10 and \%47.80 of humidifiers had distilled water in their containers, respectively, which was statically significant $(P=0.04)$. Active and connected ventilators to patient that had humidifier system, connective tubes connected to inspiratory arm and humidifier's container with distilled water simultaneously were formed $\% 26.60$ and $\% 23.50$ of ventilators, the difference was not statically significant $(\mathrm{P}=0.37)$. Nursing education for proper and complete usage of humidifiers in patients under ventilators had a few effect that could be caused by: the lack of the supply of humidifier system, the high amount of duties, the personnel shortages, the low motivation of nurses, the lack of personnel attention to the learning and employing their own knowledge and the lack of the knowledge of nurses about the research.
\end{abstract}

Keywords: Ventilator, Humidifier System, Nursing Education and Inspiratory Humidity.

The humidity of inhaled air is provided physiologically by airways ${ }^{1}$. The humidity present in the airways causes the softness and the dilution

\footnotetext{
* To whom all correspondence should be addressed. Mob.: 0989124806577;

E-mail: ahmadik@mums.ac.ir
}

of respiratory tract secretions, and while maintaining the optimal performance of airway cilia which play an important role to discharge the secretions, it prevents drying of the secretion, obstruction and its complications ${ }^{2}$.

Airway intubation or tracheostomy removes moisturizing the inhaled air by upper 
airway ${ }^{3}$. Patients with airway intubation or patients who receive dry inhaled gases with a high flow and volume encounter a reduction in the humidity of inhaled air ${ }^{4}$. Therefore, the physiological steam of breathing air should be supplied in these patients with steam humidifier ${ }^{5}$. One of these methods is the use of thermal humidifier devices which are embedded in inspiratory arm of ventilation devices. In the absence of moisture needed in the respiratory tract, the airway secretions become concentrated, sticky and dried, thus the phlegm flow from the distal parts to the proximal airway reduces or even stops by ciliary ${ }^{7}$. However, drying the airway mucosa leads to the disruption of ciliary movement and the airway irritation ${ }^{8}$. The use of mechanical ventilation within a few days, likely leads to the retention of airway secretions ${ }^{9}$, which gradually causes airway obstruction and results in atelectasis or pneumonia ${ }^{10,11}$. Dried phlegm gets into the btracheal tube and obstructs it partially or wholly ${ }^{12}$. In the following, the patient will suffer airway inflammation or ulcers, fever, cough, bronchospasm, respiratory distress, hypoxia or the acid-base disorders ${ }^{13,}{ }^{14}$. Nevertheless, the patient not only remains intubated for long-term but also the length of ICU stay or the mortality markedly increases. The superficial study of the patients mechanically ventilated in the ICU of hospitals affiliated to Alborz University of Medical Sciences and Health Services showed many problems in the use of humidifiers devices in many cases, which most notably include: the lack of air humidifier device, the lack of water supply needed for the device, the lack of connections and connective tubes, the lack of the connection of humidifier device to the respiratory circuit, and not setting of the humidifier device in inspiratory arm.

Inhaled gases gradually saturate with water vapor up to $90-80 \%$ to reachc area. This figure is $60 \%-70 \%$ in case of breathing through the mouth. The pulmonary function and the cleansing speed of ciliay in the airways in $100 \%$ relative humidity is very effective ${ }^{2}$. The physiological humidity or $100 \%$ saturation of inhaled air with water vapor is provided by the evaporation about $44 \mathrm{mg} \mathrm{H} 2 \mathrm{O} / \mathrm{L}$ water ${ }^{16,15,9}$.

Standard humidity of inhaled air in England is $33 \mathrm{mg} \mathrm{H}_{2} \mathrm{O} / \mathrm{L}^{16,15}$. The active thermal humidifier of ventilators should at least provide 30 $\mathrm{mg} / \mathrm{L}$ water vapor at a temperature of $31-35^{\circ} \mathrm{C}^{16}$. In expiratory only $25 \%$ of the added humidity is recovered during inhale, therefore, $75 \%$ of the missing humidity should be replaced. If the inhaled gases be dried and the exhaled gases be completely saturated with water vapor, the average daily amount of waste via the respiratory tract in adults will be $300 \mathrm{ml}$. Normally, about half of this figure is maintained in breathing room air through the nose. The humidity of inhaled air decreases in case of the use of a high oxygen flow ${ }^{4}$, increased ventilation, the use of dried inhaled gases and the use of tracheal tube. The reduction of the moisture content of the inhaled gas leads to the dryness of airway, increased concentration and the viscosity of airway secretions ${ }^{6}$, the dysfunction of cilia ${ }^{8,7}$, the inflammation and the scarring of airways caused by cellular level destruction ${ }^{13,9}$, the destruction of pulmonary tissue ${ }^{10}$, bronchospasm, atelectasis, which results in hypoxia ${ }^{14}$ and an increased risk of pulmonary infection ${ }^{10}$. The dried and sticky secretions enter into the tracheal tube and cause the formation of a layer in its wall ${ }^{11}$.

If the effective diameter of tracheal tube reduces, in turn, the flow of resistance gas increases, the flow of inhaled gased in particular the exhaled gases reduces, and therefore, the work of breathing increases, thus the activity of respiratory muscles increases, and oxygen consumption and carbon dioxide production increase by the muscles. The process not only helps the patient's hypoxia but also the increase of carbon dioxide emissions causes respiratory acidosis, tachypnea, sympathetic stimulation, myocardial muscle acidosis and thus reduces the myocardial contractility. In severe cases, the mucus formed in the wall of tracheal tube leads to the airway obstruction ${ }^{12,8}{ }^{8}$. These problems and incidents will be more severe especially in mechanical breathing with a high flow inhalation, long-term breathing, sensitive airways such as asthma and various respiratory tract pathology ${ }^{10}$. The humidification of respiratory gases is a standard care for respiratory devices and is recommended to control airway secretions. The application of thermal humidifiers to soften the concentrated and sticky secretions are superior to other methods employed to supply the air humidity such as Heat and Air humidity Exchange filters (HME) ${ }^{17}$. No research is registered on the topic of 
this project in medical electronic references. In this project, theoretical and practical trainings will be given the nursing staff for the proper operation of humidifiers to examine the effect of training in nurses. With implementing the results obtained in this study in ICU level, all complications and adverse consequences resulted from the failure in the proper use of humidifier devices in ventilators can be prevented, and not only the duration of hospitalization ICU will significantly be reduced but also the mortality of ICU patients will be reduced.

\section{MATERIALANDMETHODS}

This research is a Clinical Trial study. The study population included all ventilators connected to the patients admitted to intensive care units. The ventilators which were turned on and connected to the patients were enrolled in the study and the ventilators disabled were excluded. Sampling was done as available, so that a researcher was periodically and randomly present in the research area and enrolled the patients connected to the ventilator till the completion of study sample. Coinciding with the visit of patients under ventilation, their humidifier system was checked in terms of the presence of humidifier device, the presence of water within the container, the presence of flexible pipe specific to the humidifier, the connection of device to the breathing circuit and the placement of humidifier system in the inspiratory arm pathway. The results were recorded in the questionnaire prepared for this purpose. The data collected in the questionnaire was enteried into SPSS software and the frequency of the effect of nursing education on the proper application of humidifier was expressed by descriptive statistics in terms of numbers and percentages. The comparison of the effect of nursing education and its subcategories was done using chi-square and Fisher's tests.

\section{RESULTS}

In this study, without prior informing to the nursing staff about the research project, 327 active and connected ventilator devices were investigated in terms of the proper usage of humidifier systems in intensive care units, and
Table 1. The comparison of the presence of humidifier device on ventilators in both pre and post-training groups

\begin{tabular}{llll}
\hline $\begin{array}{l}\text { The presence of } \\
\text { humidifier device }\end{array}$ & Yes & No & Total \\
\hline $\begin{array}{llll}\text { Pre-training group } \\
\text { NumberPercentage }\end{array}$ & 229 & 28 & 327 \\
post-training group & 270 & $5.40 \%$ & $100 \%$ \\
NumberPercentage & $82.60 \%$ & $17.40 \%$ & $100 \%$ \\
\hline
\end{tabular}

Table 2. The comparison of the presence of connective tubes on the humidifier devices in both pre- and post-training groups

\begin{tabular}{llll}
$\begin{array}{l}\text { The presence of connective tubes } \\
\text { on the humidifier devices }\end{array}$ & Yes & $\begin{array}{l}\text { Total } \\
\text { No }\end{array}$ \\
\hline $\begin{array}{l}\text { Number } \\
\begin{array}{l}\text { Percentage } \\
\text { post-training group }\end{array}\end{array}$ & $\begin{array}{l}49.80 \% \\
\text { Number } \\
\text { Percentage }\end{array}$ & $50.20 \%$ & $100 \%$ \\
& $65.20 \%$ & $34.80 \%$ & $100 \%$ \\
\hline
\end{tabular}

Table 3. The comparison of the connection of humidifier devices to the respiratory circuit in both pre- and post-training groups

\begin{tabular}{|c|c|c|c|}
\hline \multicolumn{2}{|c|}{$\begin{array}{l}\text { The connection of humidifier } \\
\text { devices to the respiratory circuit }\end{array}$} & Yes & $\begin{array}{l}\text { Total } \\
\text { No }\end{array}$ \\
\hline $\begin{array}{l}\text { Pre-training group } \\
\text { Number }\end{array}$ & 124 & 25 & 149 \\
\hline Percentage & $83.20 \%$ & $16.80 \%$ & $100 \%$ \\
\hline $\begin{array}{l}\text { post-training group } \\
\text { Number }\end{array}$ & 136 & 40 & 176 \\
\hline Percentage & $77.30 \%$ & $22.70 \%$ & $100 \%$ \\
\hline
\end{tabular}

Table 4. The comparison of the connection of humidifier devices in the inspiratory arm pathway in both pre- and post-training groups

\begin{tabular}{llll}
\multicolumn{2}{l}{$\begin{array}{l}\text { The connection of humidifier devices } \\
\text { in the inspiratory arm pathway }\end{array}$} & Yes & \multicolumn{2}{l}{ Total } \\
& & No \\
\hline $\begin{array}{l}\text { Pre-training group } \\
\text { Number }\end{array}$ & 120 & 4 & 124 \\
$\begin{array}{l}\text { Percentage } \\
\text { post-training group }\end{array}$ & $96.80 \%$ & $3.20 \%$ & $100 \%$ \\
$\begin{array}{l}\text { Number } \\
\text { Percentage }\end{array}$ & $93.40 \%$ & $6.60 \%$ & $100 \%$ \\
\end{tabular}


then the education courses of the proper use of humidifiers were held.

In the following, as the first step, without prior notice informing to the nursing staff, 327 ventilator devices were studied and the results showed that the ventilators had humidifier system before and after nursing education in $91.40 \%$ and $82.60 \%$ of the cases, which significantly was decreased $(p=0.001)$. Before and after nursing education, the humidifier systems had connections and connective tubes in $49.80 \%$ and $65.20 \%$ of the cases, respectively, which significantly was increased $(p=0.00)$. Before and after nursing education, the humidifiers were connected to the respiratory circuit in $83.20 \%$ and $77.20 \%$ of the cases, respectively, in which there was no statistically significant difference $(p=0.18)$. The humidifiers were properly placed in the inspiratory arm in the both groups in $96.80 \%$ and $93.40 \%$ of the cases, respectively, in which there was no statistically significant difference $(p=0.21)$.

The humidifiers were filled with distilled water in the both groups in $39.10 \%$ and $47.80 \%$ of the cases, respectively, in which there was

Table 5. The comparison of the number of humidifier devices containing distilled water in both pre- and post-training groups

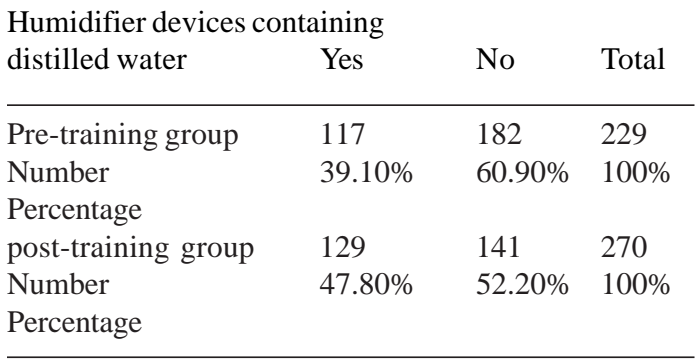

Table 6. The comparison of ventilators with a complete set of humidifier device connected to the patients in both pre- and post-training groups

Ventilators containing a complete set of humidifier device

\begin{tabular}{llll}
\multicolumn{2}{l}{ with a proper connection Yes } & No & Total \\
\hline Pre-training group & 87 & 240 & 327 \\
$\begin{array}{l}\text { Number } \\
\text { Percentage }\end{array}$ & $26.60 \%$ & $73.40 \%$ & $100 \%$ \\
post-training group & 77 & 250 & 327 \\
$\begin{array}{l}\text { Number } \\
\text { Percentage }\end{array}$ & $23.50 \%$ & $76.50 \%$ & $100 \%$ \\
\hline
\end{tabular}

statistically significant difference $(p=0.04)$. Enabled and turned on ventilators which simultaneously had humidifier device, connectors and connective tubes connected to the inspiratory arm in the respiratory circuit and water in humidifier container contained $26.60 \%$ and 23.505 of the ventilators and showed no statistically significant decrease

\section{DISCUSSION}

Despite many advances in the field of ventilators and equipping with them humidifier systems, there are still some drawbacks in the full and accurate usage of inhaled air humidifier systems, such as the lack of air humidifier device, the lack of water supply needed for the device, the lack of connections and connective tubes, the lack of the connection of humidifier device to the respiratory circuit, and not setting of the humidifier device in inspiratory arm. The aim of this study was to evaluate the effect of education on the modification of the above-mentioned drawbacks in the use of humidifiers is in intensive care units. No specific study has been done so far in this regard. The results indicated that the nursing education was significantly beneficial in relation to the use of distilled water in the humidifier and the installation of connections and connective tubes, while the use of ventilators with humidifier device showed a significant reduction in the posttraining group which represents the ineffectiveness of the training. The placement of the humidifier device in the respiratory circuit and inspiratory arm was decreased in the post- training group, but the reduction was not statistically significant.

In total, applying a complete and correct set of humidifier device in the enabled and connected ventilator to the patients was decreased in post- training group compared to pre- training group, but it was not statistically significant showing that the education was ineffective. In this study, the nursing education in the proper usage of humidifier device showed no acceptable results, which could be due to: the lack of the supply of humidifier system by the authorities, the high amount of duties and the personnel shortages, the low motivation of nurses, the lack of personnel attention to the learning and employing their own knowledge and the lack of the knowledge of nurses 
about the research. It is suggested that the present plan be reexamined followed by supplying a complete set of humidifier system with the prior informing to the nursing personnel and their informed retraining in order to measur the teachability of nurses.

\section{REFERENCES}

1. Jackson C.Humidification in the upper respiratory tract: A physiological overview. Intensive Crit Care Nurs.1996;12: 27-32.

2. Dery R. The evalution of heat and moisture in the respiratory tract during anaesthesiawith a non-rebreathing system. CanaJ Anaesth. 1972; 20: 269.

3. Ballard $\mathrm{K}$, et al. Humidification for ventilated patients. Intensive Crit Care Nurs. 1992; 8(1): 2-9.

4. ShellyM. Measurement of humidification. British journal of intensive care. 1997; 1: 1-6

5. Henze D, et al. ArtificialHumidification of inspired gas status of knowledge and technique. Reanim. 1997; 22(6): 153-8.

6. Turner D. Efficiency of heat and moisture exchangers. Anaesthesia. 1987;42:P117-9.

7. Conway J.The effects of humidification for patients with chronic obstructive airway disease physiotherapy. 1992; 78(2): 97-101.

8. JoyntGM ,Lipman J. Humidification in intensive care. S Afr surg. 1994; 32(1):23-30.

9. Sottiaux TM. Consequences of under - and over -humidification.Respir Care Clin N Am. 2006; 12(2): 233-52.

10. Schulze A. Respiratory gas conditioning and humidification. In:Clin Perinatal. 2007;34:1933,ISSN0095-5108.

11. Villafane M. Gradual reduction of endotracheal Tube diameter during mechanical ventilation via different humidification devices. Anaesthesiology. 1996; 85: P1341-9.

12. Martin C. Heat and moisture exchangers and vaporising humidifiers in the Intensive care unit.Chest. 1990; 97: 144-49

13. Hough A. Physiotherapy in respiratory care. 2nd Edition, London:Chapman and Hahh. 1996;

14. Jackson C, Webb A. An evaluation of the heat and moisture exchanger performance of four ventilator circuit filters. Intensive Care Med. 1992; 18: 264-268.

15. TarnowMordi WO et al. Evidence of inadequate humidification of Inspired gas during artificial ventilation of newborn babies in the britishIsIes Lancet. 1986; 2(8512):909-10.

16. Restrepo RD, Walsh BK. Humidification during invasive and noninvasive mechanical ventilation respiratory care. Respir care. 2012; 57(5):7828.

17. Branson RD. Secretion management in the mechanically ventilated patient. Respir care. 2007; 52(10):1328-42; discussion:1342-7. 